\title{
Differential reinforcement of specific lick rates in the rat*
}

\author{
STEPHEN C. PIERSON $\dagger$ \\ and \\ ROBERT W. SCHAEFFER $\dagger \dagger$ \\ Florida State University, Tallahassee, Fla. 32306
}

Lick rates in rats were differentially reinforced, using an operant conditioning procedure in which specific lick rates, when maintained for specific temporal durations, were reinforced with the opportunity to run in an activity wheel. This operant conditioning paradigm is referred to as differential reinforcement of high rates of responding $(\mathrm{DRH})$. Between and within Ss, lick rate variability did not exceed one lick for all DRH conditions tested in which the time base was $1 \mathrm{sec}$ or less. Specific momentary lick rates were successfully reinforced for all Ss tested, but DRH conditioning did not produce higher momentary lick rates than the range of lick-rate values normally observed in baseline conditions.

All evidence presently available suggests that the licking response in rats occurs at a relatively constant momentary rate. Stellar \& Hill (1952), the earliest investigators to explore rate of licking in the rat, found that (a) rats drink at a relatively constant rate or not at all. (b) the average rate of licking is $6-7 \mathrm{laps} / \mathrm{sec}$, and (c) this rate is independent of fluid deprivation levels. Davis \& Keehn (1959) further substantiated the constancy of the lick rate in the rat by presenting evidence that the average lick rate was constant for saline, sucrose, and saccharin solutions. In 1960, Davis and Arnold concluded that slight intersession and individual differences in lick rate, of the order of about 1 lick/sec, did exist.

Further evidence that lick rates in the rat are largely independent of environmental influence was presented by Schaeffer \& Premack (1961). They found that neonatal rats, raised without an opportunity to drink, upon their first contact with fluids displayed a mean lick rate identical to that of adults. Unlike previous investigators, Schaeffer and Premack showed that careful analysis of momentary lick rate within bursts of over $1 \mathrm{sec}$ duration yielded initial actual rates of licking for some animals as high as 9.0 licks/sec and actual terminal rates within the same burst as low as 5.2 licks/sec. which averaged to a mean lick rate for the entire lick burst of 6.6 licks/sec. As have other investigators, however, they found that both the mean and modal lick rates for rats were 6.7 licks/sec.

*Supported by Public Health Research Grants MH-08775 and MH-12025 from the National Institute of Mental Health, $R$. W. Schaeffer, principal investigator. The data upon which this report is based were submitted by the senior author (S.C.P.) under the direction of the junior author (R.W.S.) in partial funfill fulfillment of the thesis requirement for the master's degree at Florida State University.

+Now with the Department of Ecology and Behavioral Biology, University of Minnesota, St. Paul, Minn. 55101.

++ Now with the Department of Psychology, Auburn University, Auburn, Ala. $\mathbf{3 6 8 3 0}$.
Further evidence for the highly invariant, elicited, reflexive nature of licking in the rat has been provided by Snyder \& Hulse (1961), DeBold, Miller, \& Jensen (1965), Boice \& Denny (1965), Hulse (1966), and Schaeffer \& Smith (1966). These studies, in addition to revealing that the lick response fatigued, could be classically conditioned, and, once initiated, was reflexive, all reported that lick rate was essentially constant. Furthermore, the reflexive properties of momentary lick rate were not affected by radiation doses 10 times the strength needed to produce aversion to normally preferred saccharin solutions (Schaeffer \& Smith, 1966).

Recently, Corbit \& Luschei (1969) used a computer to measure interlick intervals in milliseconds and found that neither different deprivation schedules, preferred taste stimulation, nor aversive taste stimulation affected the interlick interval. The mean rate of licking, as measured by this highly precise method, equalled 6.5 licks/sec, which compares favorably with the rates found by earlier investigators, using considerably less precise instrumentation than the computer.

Most early investigations of the licking response were concerned with providing evidence for the constancy of the lick rate and demonstrating its genetic, reflexive nature. Although licking has recently been used as an instrumental response in operant conditioning experiments, there have been no reported attempts to modify lick rate by using differential rate of reinforcement for high (DRH) rates of licking. Such an investigation would be related, theoretically and procedurally, to other attempts to operantly condition autonomic and reflexive behaviors. Trowill (1967) provided evidence that the heart rate of an artificially respirated rat can be increased or decreased by a factor of $5 \%$ if rates faster or slower than the typical normal (i.e., average) heart rate are rewarded. Miller \& DiCara (1967) instrumentally conditioned heart rate changes of $20 \%$. It is important to note that only normally occurring momentary variations above and below the average constant heartbeat rate were selected for reinforcement by these investigators. It is also important to note that in neither experiment was the rate of heartbeat successfully conditioned to beat at some randomly selected rate greater than or less than the absolute range of values observed in baseline conditions. Similarly, in the present investigation, specific lick rate values observed in the rat under normal baseline conditions were selected as instrumental lick rate values which were reinforced, thereby demonstrating that momentary lick rates can be brought under specific environmental control.

METHOD
Subjects
The Ss were three female goldenhood rats. approximately 120

Subjects

The woldenhood rats. approximately 120 
Table 1

Percentage of Reinforcements Earned at Each DRH Lick Rate Requirement for Ss 1, 2, and 3*

\begin{tabular}{|c|c|c|c|c|c|c|}
\hline \multirow{2}{*}{$\begin{array}{l}\text { Minimum } \\
\text { Responses/ } \\
\text { Maximum } \\
\text { Time } \\
\end{array}$} & \multicolumn{3}{|c|}{$\begin{array}{c}\text { Ascending } \\
\text { Order }\end{array}$} & \multicolumn{3}{|c|}{$\begin{array}{c}\text { Descending } \\
\text { Order }\end{array}$} \\
\hline & S 1 & S 2 & 53 & S 1 & S 2 & S 3 \\
\hline $\begin{array}{l}14 / 2.0 \\
15 / 2.0 \\
16 / 2.0 \\
17 / 2.0 \\
18 / 2.0\end{array}$ & $\begin{array}{r}100 \\
60 \\
00 \\
00 \\
00\end{array}$ & $\begin{array}{r}100 \\
100 \\
80 \\
20 \\
00\end{array}$ & $\begin{array}{r}100 \\
100 \\
80 \\
20 \\
00\end{array}$ & $\begin{array}{r}100 \\
40 \\
00 \\
00 \\
00\end{array}$ & $\begin{array}{r}100 \\
100 \\
60 \\
20 \\
00\end{array}$ & $\begin{array}{r}100 \\
100 \\
80 \\
20 \\
00\end{array}$ \\
\hline $\begin{array}{r}7 / 1.0 \\
8 / 1.0 \\
9 / 1.0 \\
10 / 1.0\end{array}$ & $\begin{array}{r}100 \\
100 \\
20 \\
00\end{array}$ & $\begin{array}{r}100 \\
100 \\
20 \\
00\end{array}$ & $\begin{array}{r}100 \\
100 \\
60 \\
00\end{array}$ & $\begin{array}{r}100 \\
80 \\
20 \\
00\end{array}$ & $\begin{array}{r}100 \\
100 \\
60 \\
00\end{array}$ & $\begin{array}{r}100 \\
100 \\
20 \\
20\end{array}$ \\
\hline $\begin{array}{l}3 / 0.5 \\
4 / 0.5 \\
5 / 0.5 \\
6 / 0.5\end{array}$ & $\begin{array}{r}100 \\
100 \\
60 \\
00\end{array}$ & $\begin{array}{r}100 \\
100 \\
40 \\
00\end{array}$ & $\begin{array}{r}100 \\
100 \\
80 \\
00\end{array}$ & $\begin{array}{r}100 \\
100 \\
80 \\
00\end{array}$ & $\begin{array}{r}100 \\
100 \\
80 \\
00\end{array}$ & $\begin{array}{r}100 \\
100 \\
100 \\
00\end{array}$ \\
\hline $\begin{array}{l}2 / 0.4 \\
3 / 0.4 \\
4 / 0.4 \\
5 / 0.4 \\
6 / 0.4\end{array}$ & $\begin{array}{r}100 \\
100 \\
100 \\
00 \\
00\end{array}$ & $\begin{array}{r}100 \\
100 \\
100 \\
00 \\
00\end{array}$ & $\begin{array}{r}100 \\
100 \\
100 \\
20 \\
00\end{array}$ & $\begin{array}{r}100 \\
100 \\
100 \\
00 \\
00\end{array}$ & $\begin{array}{r}100 \\
100 \\
100 \\
00 \\
00\end{array}$ & $\begin{array}{r}100 \\
100 \\
100 \\
00 \\
00\end{array}$ \\
\hline $\begin{array}{l}2 / 0.3 \\
3 / 0.3 \\
4 / 0.3 \\
5 / 0.3\end{array}$ & $\begin{array}{r}100 \\
100 \\
00 \\
00\end{array}$ & $\begin{array}{r}100 \\
100 \\
00 \\
00\end{array}$ & $\begin{array}{r}100 \\
100 \\
60 \\
00\end{array}$ & $\begin{array}{r}100 \\
100 \\
00 \\
00\end{array}$ & $\begin{array}{r}100 \\
100 \\
60 \\
00\end{array}$ & $\begin{array}{r}100 \\
100 \\
80 \\
00\end{array}$ \\
\hline $\begin{array}{l}2 / 0.2 \\
3 / 0.2 \\
4 / 0.2\end{array}$ & $\begin{array}{r}100 \\
00 \\
00\end{array}$ & $\begin{array}{r}100 \\
00 \\
00\end{array}$ & $\begin{array}{r}100 \\
60 \\
00\end{array}$ & $\begin{array}{r}100 \\
00 \\
00\end{array}$ & $\begin{array}{r}100 \\
20 \\
00\end{array}$ & $\begin{array}{r}100 \\
60 \\
00\end{array}$ \\
\hline
\end{tabular}

*Each DRH lick rate requirement is shown in terms of the minimum number of lick responses permitted divided by the maximum time interval allowed for responses to occur. At any given $D R H$ lick rate requirement, the $D R H$ values were tested in both an ascending and a descending order.

days old, supplied by F. T. Crawford at Florida State University. All Ss were maintained on ad lib food and water and were individually housed in Hoeltge HB-11A cages under constant light and temperature conditions.

\section{Apparatus}

The activity-wheel test chamber which was employed in this investigation has been described in detail by Schaeffer (1966). Essentially, the chamber allows for the observation, measurement, and arrangement of reinforcement contingencies between running and licking behaviors of rats.

The recording of the number of $180-\mathrm{deg}$ wheel turns, the number of licks emitted, and the number of reinforcements earned, and the programming of the paired free-operant (PFO) conditions (drinking tube and wheel freely and concurrently available) and the lick-to-run contingencies (opportunity to run contingent upon the completion of the licking-response requirements) were accomplished by standard electromechanical circuitry and recorded on an Esterline-Angus Model A609C analog-event recorder. Massey-Dickinson solid state components were employed for all schedule programming of lick rate requirements. A high-speed Esterline-Angus Model 620y event recorder, with the chart moving at the rate of $1.805 \mathrm{~cm} / \mathrm{sec}$, was used to record graphically all licking.

A light panel, consisting of three Dialco 931-207 light assemblies mounted paralled to each other, was positioned above the drinking tube. The center light indicated drinking tube availability to the Ss; the illumination of the remaining two lights signaled the availability of the wheel (nonbraked).

A $4 r$ concentration of sucrose solution measured in weight/volume units was used in the drinking reservoirs, not only to increase the probability of drinking. but avoid the use of fluid-deprivation schedules. White noise and a blower to circulate fresh air were also employed in the test chamber.

The drink spout was a standard commercially available Wahmann stainless steel tube with a $.38-\mathrm{cm}$ orifice. The tube was positioned so as to probibit nose-tube contacts, but did not demand an unusual lick topography. The diameter of the hole through which the $S s$ licked was $1.27 \mathrm{~cm}$.

\section{Preliminary Training}

\section{Procedure}

During the initial adaptation period, the wheel and the tube were concurrently and freely available to the Ss for $15-\mathrm{min}$ daily sessions. Baseline measures of the total number of wheel revolutions, total number of licks, and total fluid ingested were taken. All three cue lights were illuminated during this phase. When the number of wheel revolutions had stabilized (the number of wheel turns for the last day was within the range of the totals for the 3 preceding days), a lick-to run contingency was instituted. All Ss were shaped to lick to have the opportunity to run by initially employing low FR requirements. Ss were then moved to a FR 20, at which point they remained. A FR 20 was chosen in order to ensure that instrumental licking would occur for at least $2 \mathrm{sec}$ on each lick trial. On contingent trials, the drinking tube availability light was illuminated until the completion of the FR-20 requirement, at which time the wheel became available for a 15 -sec period of contingent time (CT), the wheel availability lights were illuminated, and the drinking tube was withdrawn for the 15 -sec period of CT. At the end of the CT period, the drinking tube was made available to $S$ and a new trial was begun.

\section{Experimental Design}

After preliminary training, a rate requirement was substituted for the FR-20 lick response requirement. The specific lick rate values tested are shown in the column labeled "DRH Values" in Table 1. Only one time base was tested in any given daily session, but each $S$ was given five consecutive trials at each time-based DRH criterion. A trial was defined as a burst of licking terminated at least $2 \mathrm{sec}$ before a subsequent lick burst was initiated. Thus, each trial did not necessarily end in reinforcement for the $S$, and two consecutive nonreinforced trials could be separated by as little as $2 \mathrm{sec}$. After five trials on the time-based DRH criterion, regardless of whether or not the $S$ was successful in obtaining reinforcement, the DRH criterion was programmed at a low value (five licks required in $1 \mathrm{sec}$ ). Each $S$ was allowed to complete the remainder of the $15-\mathrm{min}$ daily session with this low-value DRH criterion in effect.

In an attempt to control for the effects of fatigue, an ascending and descending method of presentation was employed for each DRH value indicated in Table 1 . Only after both the ascending and descending methods of presentation were completed for a given time value was another time base tested.

After all of the DRH lick-rate-requirement values had been tested at least twice, a final baseline phase was begun, in which the wheel and tube were both freely and concurrently available to the Ss. Esterline-Angus records of all licking, both during the baseline and contingency periods, were obtained so as to provide a record of lick rate, the number of successful and unsuccessful attempts to obtain reinforcement, and total number of lick bursts.

\section{RESULTS AND DISCUSSION}

The percentage of reinforcements earned at each programmed DRH lick rate requirement is presented for each $S$ in Table 1. All three Ss were able to earn 
reinforcements when required to emit a minimum number of 14 responses within the 2.0-sec time base employed. The maximum number of licks that $\mathrm{S} 1$ could emit in $2.0 \mathrm{sec}$ was 15 , whereas the maximum number of licks that Ss 2 and 3 were able to emit in $2.0 \mathrm{sec}$ was 17 .

When the time base was reduced from 2.0 to $1.0 \mathrm{sec}$, all Ss were able to emit 9 licks in $1.0 \mathrm{sec}$, but only S 3 was able to emit a total of 10 licks in $1.0 \mathrm{sec}$. When the time base was decreased to $0.5 \mathrm{sec}$, all three Ss were able to emit 5 responses in $0.5 \mathrm{sec}$, but none were able to emit 6 licks in $0.5 \mathrm{sec}$. When the time base was reduced to $0.4 \mathrm{sec}$, all Ss were able to emit 4 licks in this period. On only $20 \%$ of the trials was S 3 capable of emitting 5 responses in $0.4 \mathrm{sec}$. At all other values tested at the 0.4-sec time base, this S's performance was not distinguishable from the performance of either $S 1$ or S 2 .

When a base of $0.3 \mathrm{sec}$ was employed, all three Ss were able to emit 3 responses in the $0.3-\mathrm{sec}$ time period. Although on some of the trials Ss 2 and 3 were capable of emitting 4 licks in the $0.3-\mathrm{sec}$ period, no $\mathrm{S}$ was capable of emitting a total of 5 licks in $0.3 \mathrm{sec}$. At the $0.2-\mathrm{sec}$ time base tested, all Ss were capable of emitting 2 licks in $0.2 \mathrm{sec}$; no Ss were able to emit 4 licks in 0.2 sec, and only $S 1$ failed to emit a total of 3 licks in $0.2 \mathrm{sec}$ on any of the test trials given at this value. Examination of the data presented in Table 1 reveals that there were no observable systematic effects on lick rate that could be attributed to the ascending or descending order of presentation of the test trials.

From all of the data available, it is evident that a small amount of variability in mean lick rate and lick rate ranges exists, both between and within Ss. Variability between and within Ss, however, is no less striking than the comparability of specific momentary lick rates that can be conditioned. For all conditions tested in which the time base was $1.0 \mathrm{sec}$ or less, the difference in conditionable lick rates between and within Ss was, at most, only one lick for each of the conditions tested.

If the reader will examine the DRH values shown in Column 1 of Table 1 and divide the minimum number of responses required by the maximum time permitted, a value that has been described as a "momentary lick rate" (Schaeffer \& Premack, 1961) for each time base tested will be obtained. These rates are described as momentary lick rates, even though they are arithmetical mean values at all time values greater than $1 \mathrm{sec}$, to direct attention to actual lick rates per second as opposed to lick rates averaged over more than $1 \mathrm{sec}$. The reader will further note that this momentary lick rate systematically increases as the time base for the DRH contingency is decreased from 1.0 to $0.2 \mathrm{sec}$. Clearly, if the animal were capable of sustaining its initial momentary rates of licking in the first second of drinking for periods in excess of $1.0 \mathrm{sec}$, all Ss would lick at rates substantially in excess of $10 / \mathrm{sec}$. Initial momentary rates of licking decayed progressively in the first second in such a manner that no $\mathrm{S}$, in spite of its high initial momentary
Table 2

Maximum Number of Licks that Occurred in Each Time Base Interval Underlying the DRH Lick Contingencies Employed in the Experiment*

\begin{tabular}{|c|c|c|c|c|c|c|c|c|c|}
\hline \multirow{3}{*}{$\begin{array}{l}\text { Time } \\
\text { Base } \\
\text { (Sec) }\end{array}$} & \multicolumn{4}{|c|}{ Absolute Maximum } & \multirow{2}{*}{\multicolumn{2}{|c|}{$\frac{\text { Number }}{\mathrm{S} 2}$}} & \multirow{2}{*}{\multicolumn{3}{|c|}{$\frac{\text { s Observed }}{\text { S } 3}$}} \\
\hline & \multicolumn{3}{|c|}{$\mathrm{S} 1$} & \multirow[b]{2}{*}{ A } & & & & & \\
\hline & A & B & $\mathrm{C}$ & & B & C & A & B & $\mathrm{C}$ \\
\hline 2.0 & 14 & 15 & 15 & 15 & 17 & 16 & 17 & 17 & 17 \\
\hline 1.0 & 8 & 9 & 9 & 8 & 9 & 9 & 9 & 10 & 9 \\
\hline 0.5 & 5 & 5 & 5 & 5 & 5 & 5 & 5 & 5 & 5 \\
\hline 0.4 & 4 & 4 & 4 & 4 & 4 & 4 & 4 & 5 & 5 \\
\hline 0.3 & 3 & 3 & 3 & 3 & 4 & 3 & 3 & 4 & 4 \\
\hline 0.2 & 2 & 2 & 2 & 2 & 3 & 3 & 3 & 3 & 3 \\
\hline
\end{tabular}

*The absolute maximum number of licks in identical intervals in the preexperimental and postexperimental periods are also shown to permit comparisons between the maximum lick rates that occurred during the contingency (B) and the maximum lick rates that occurred in the preexperimental $(A)$ and postexperimental (C) baseline conditions.

rates of licking, could sustain a rate of more than $10 / \mathrm{sec}$.

The results thus far presented have demonstrated that the specific momentary rates of licking may be controlled by the reinforcing consequences of a highly probable running response when it is made contingent upon a less probable licking response. This generalization is given more validity by the present finding that no Ss failed to utilize the reinforcer every time it became available in the daily DRH trials, both at high and low DRH values. The results presented in Table 2 , however, indicate that none of the specific momentary rates conditioned were in excess of rates normally found to occur in rats. The rapid decay in lick rate noted to occur in the rat in the first second of licking was clearly not altered by the conditioning process. There was no indication that the procedures employed at any time produced a rate of licking higher than rates observed in the original baseline condition. Rather, conditioning merely increased the frequency with which lick bursts of a specific rate occurred relative to the frequency observed in a baseline condition.

That lick rates higher than those that normally occur in baseline conditions could not be conditioned is not at all disturbing since this finding is similar to the results found by investigators who have performed successful operant conditioning of heart rates (Trowill, 1967; DiCara \& Miller, 1969; Engel \& Gottlieb, 1970). In all these investigations of heart-rate conditioning only small normally occurring (i.e., $10 \%$ or $20 \%$ ) variations in baseline heart rates were conditioned. It should be noted that the specific heart rates conditioned are often difficult to determine from these studies since base rates, normal fluctuations in heart rate, and specific experimental proceedings used to condition heart rates are not sufficiently described to permit replication of the study, but, even given the poor description, it is clear that these studies employ only a very limited range of heart rate values and a small variation in heart rate as the instrumental response required for reinforcement. By 
comparison, the present study examined essentially the entire range of lick values that has ever been observed to occur in the rat, and selectively and successfully conditioned essentially the entire range of lick rates observed in this and previous studies as instrumental responses.

\section{REFERENCES}

Boice, R \& Denny, M. R. The conditioned licking response in rats as a function of the CS-UCS interval. Psychonomic Science, 1965, 3, 93-94.

Corbit, J. D., \& Luschei, E. S. Invariance of the rat's rate of drinking. Journal of Comparative \& Physiological Psychology, $1969,69,119-125$.

Davis, J. D. \& Arnold, E. M. M. Licking rates of albino rats. Science, 1960, 132, 739-741.

Davis, J. D., \& Keehn, J. D. Magnitude of reinforcement and consumatory behavior. Science, 1959, 130, 269-270.

DeBold, R. C. Miller, N. E., \& Jensen, D. D. Effect of strength of drive determined by a new technique for appetive classical conditioning of rats. Journal of Comparative \& Physiological Psychology, 1965, 59, 102-108.

Engel, B. T. \& Gottlieb, S. H. Differential operant conditioning

of heart rate in the restrained monkey. Journal of Comparative \& Physiological Psychology, 1970, 73, 217-225.
Hulse $S, H$ Stimulus intensity and the magnitude of the licking reflex in rats. Psychonomic Science, 1966, 6, 3-34.

Hulse, S. H. Licking behavior of rats in relation to saccharin concentration and shifts in fixed-ratio reinforcement. Journal of Comparative \& Physiological Psychology, 1967, 64, 471-484.

Miller, N. E., \& DiCara, L. Instrumental learning of heart rate changes in curarized rats: Shaping and specificity to discriminative stimulus. Journal of Comparative \& Physiological Psychology, 1967, 63, 12-19.

Schaeffer, R. W. A new device for programming contingencies between drinking, running and lever pressing. Journal of the Experimental Analysis of Behavior, 1966, 9, 529-533.

Schaeffer, R. W., \& Premack, D. Licking rates in infant albino rats. Science, 1961, 134, 1980-1981.

Schaeffer, R. W. \& Smith J. C. Lick rates in rats exposed to gamma-irradiation. Psychonomic Science, 1966, 6, 201-202.

Snyder, H. L., \& Hulse, S. H. Effect of volume of reinforcement and number of consummatory responses on licking and running behavior. Journal of Experimental Psychology, 1961, 61, 474-479.

Stellar, E., \& Hill, J. H. The rat's rate of drinking as a function of water deprivation. Journal of Comparative \& Physiological Psychology, 1952, 45, 96-102.

Trowill, J. A. Instrumental conditioning of the heart rate in the curarized rat. Journal of Comparative \& Physiological Psychology, 1967, 63, 7-11.

(Received for publication April 15, 1973.) 